\title{
The Financial And Cost Accounting Implications Of Medical Tourism
}

Paul J. Carruth, Southeastern Louisiana University, USA

Ann K. Carruth, Southeastern Louisiana University, USA

\begin{abstract}
It is estimated that the current annual U.S. investment in health care is \$2 trillion, roughly 16 percent of the gross domestic product (GDP). Of great concern is the fact that health care costs are rising at two-and-one-half times the rate of inflation in the economy. As a result, the model of health care outsourcing to less developed countries has become increasingly more attractive to individuals who pay out of pocket expenses for health care or who do not want to wait long periods for health care. Medical tourism, introduced in several countries outside the U.S. over a decade ago, is a term coined to represent those underinsured individuals who are willing to pay to travel overseas to save significant amounts of money on the same procedures offered at much greater expense through the U.S. health care system. Because quality of health care around the world varies, concern over substandard care with regard to surgery and other medical procedures is a factor to take into consideration when evaluating medical tourism. This article analyzes the cost implications of medical outsourcing abroad and discusses the financial implications of medical tourism as it relates to the cost of direct care, follow up care, and complications.
\end{abstract}

Keywords: Medical Tourism, Accounting

\section{INTRODUCTION}

$\mathscr{J}$

here are tens of millions of underinsured individuals living in the United States. This factor along with rapidly increasing health care cost and higher deductibles imposed on many insurance policies has created an increased demand for cost-effective health care options (McCallum and Jacoby, 2009). Americans are increasingly more willing to travel outside of the U.S. to take advantage of lower-cost health care options. This trend is driven by the downward economy, and stimulated by the growing demand for what many call "medical tourism". In fact the number traveling abroad for medical care is expected to increase dramatically over the next decade (Deloitte, 2008). This article analyzes the cost implications of health care, the medical outsourcing abroad of health care, and the financial implications of medical tourism.

The model of outsourcing of medical care is not a new concept. Many have traveled to Europe and other developed countries seeking health care not yet available in the United States or thought to be more advanced than what is available in the U.S. The outsourcing of medical care to less developed countries is a recent phenomenon and has been coined "medical tourism". Seeking health care in countries such as India or Indonesia is fundamentally different from the traditional model of international medical travel. Traditionally patients have journeyed from less developed nations to major medical centers in highly developed countries for medical treatment that is unavailable in their own communities (Horowitz, Rosenweig, and Jones 2007). The phrase medical tourism has come into general usage and it provides an unambiguous way of differentiating the recent phenomenon of medical tourism from the traditional model of international medical outsourcing to major medical centers. With globalization and advances in health care-related information technology, this medical tourism model of health care may be a cost effective alternative for many services previously offered only by the health care model in the US. and other developed countries. However, maintaining standards of quality that meet or exceed those in the U.S is of great concern (McCallum and Jacoby 2009). 


\section{HIGH COST OF HEALTH CARE CONTRIBUTES TO APPEAL OF MEDICAL TOURISM}

U.S. health care is costly, fragmented, and complex. Each year, new technologies, medical devices, medications, and procedures are added to the progression from research to practice - a process that sometimes takes up to 17 years. Meanwhile common surgeries such as knee replacements range in cost from $\$ 40,000-\$ 50,000$ in the U.S., yet can be performed in Costa Rica for about $\$ 10,000$ (Koster, 2009).

Health care costs continue to rise at two-and-a half times the rate of inflation in the economy. Estimates indicate that by 2016 , health care costs will reach 20 percent of the GDP. It is generally thought that health care in the U.S. is better than that available in many industrialized countries. In fact, even though the U.S. per-capita expenditures on health care are 20 percent higher than any other nation, key health indicators such as infant mortality (23rd) and life expectancy (28th) are well below many other nations.

The primary reason individuals from highly industrialized nations seek medical services in less developed countries is lower cost (Horowitz, Rosenweig, and Jones 2007). Typically, these patients are likely uninsured or underinsured middle class adults requiring elective surgical procedures not covered by their insurance and thus they must pay out of pocket costs for their health care needs.

In those countries where the government controls access to health care services, some individuals choose outsourcing of medical care to circumvent delays associated with long waiting lists (Daily Express, 2005). For example, serious delays in obtaining timely health care in Canada for certain medical interventions (such as hip and knee replacements, spinal surgery, and ophthalmologic procedures) has led to an increase in medical tourism among Canadians. Even though federal and provincial governments attempt to shorten waiting lists and provide timely care, patients often wait months to receive routine treatment (Turner, 2007). There is a growing concern among some Canadians regarding their ability to obtain prompt medical treatment. For these individuals, medical tourism provides an option for obtaining health care services provided in other countries on a more timely basis. Some patients choose to go to medical tourism destinations because they are more confident that their privacy and confidentiality will be protected by the extent of the distance traveled to receive services. Finally, but to a lesser extent, some patients choose to seek medical services abroad for the opportunity to vacation in exotic, yet affordable luxurious surroundings.

\section{ECONOMIC IMPACT OF MEDICAL TOURISM TO GLOBAL HEALTH CARE MARKETPLACE}

Although there are no definitive statistics regarding the economic impact of medical tourism, the available information suggests that a substantial number of individuals travel to developing nations for health care. It is estimated that in 2004, 1.2 million patients traveled to India for health care and 1.1 million medical tourists traveled to Thailand. (The Economic Times, July 29, 2005). An estimated 750,000 Americans went overseas for medical care in 2007, a number that is projected to rise to nearly 6 million by 2010 (2008 report from the Deloitte Center for Health Solutions). The magnitude of medical tourism to Asia measured in dollars are projected to be as much as $\$ 4.4$ billion spent by 2012, with approximately half of this revenue going to India (Appleby, 2006; Lancaster, 2004).

Projected revenue varies depending on the source of the estimates. For example, according to the Federation of Indian Chambers of Commerce and Industry, the health-care market, which includes health insurance, is expected to expand by 2012 from 22.2 billion U.S. dollars, or $5.2 \%$ of gross domestic product (GDP), to between 50 billion and 69 billion U.S. dollars, or $6.2 \%$ and $8.5 \%$ of GDP.

Medical tourism is one way that India is profiting from globalization and outsourcing. By developing the medical tourism industry, India also improves its public image. Foreigners who receive medical services in India help the country to promote itself as a business and tourism destination (Chinai and Goswami, 2007).

\section{MEDICAL TOURISM FACILITATORS}

With the realities of increased costs in the health care industry and so many not willing to wait for their "queue" in the system, medical tourism vendors are establishing entrepreneurial partnerships with employers to help 
their employees benefit from the significant savings available from medical care abroad. Medical tourism facilitation is a growing industry designed to accommodate this sector of travel. Health care travel packages cover transportation and lodging arrangements, travel visas, a host in the destination country, and arrangements specific to the medical care needs of patients. These agents act as liaisons to plan and market packages for medical tourism (Lubell, 2009). Many of the health care facilities that are used in "tourism packages" are regulated by standards similar to those in the U.S.

According to their website, The Medical Tourism Association (MTA) has launched a "pilot program" of certification of medical tourism facilitators who are involved in the coordination of care for patients traveling from one country to another. Successful members of the pilot project will receive certification for up to two years certification at that time. To date, three international and five U.S. based companies have applied for certification. In Canada, at least 15 medical tourism companies operate to provide travel packages for outsourced care. Some companies send their clients to a single medical facility in a particular country, while other agencies work with clients to choose their destinations (Turner, 2007).

\section{FINANCIAL BENEFITS TO PATIENTS}

The global market response to the Western demand for less costly medical procedures is the development of outsourcing medical procedures at a fraction of the cost incurred in the United States. According to the medicaltourismasociation.com website, costs associated with common surgeries in the U.S. are substantially higher than in medical tourism destinations. For example, a heart bypass costs $\$ 144,000$ in the U.S., while in Thailand the same procedure costs $\$ 24,000$, and even less in India $(\$ 8,500)$. Plastic surgery, costly in the U.S., can be obtained in Columbia for less than a fourth of the cost in U.S. Many individuals seek care as medical tourists because insurance companies do not cover certain procedures. For example, lap band procedure, an elective medical procedure to help individuals loose weight, costs $\$ 5000$ in Jordan compared to $\$ 30,000$ in the U.S. Other comparisons can be found at www.medicaltourismassociation.com. With escalating costs not covered by insurance companies, many are realizing that the out of pocket expenses associated with care outsourced to other countries can be significantly less than deductibles and other disallowed expenses required by U.S. based insurance companies.

\section{HEALTH CARE INSURANCE COMPANIES' RESPONSES}

It is estimated that the current annual U.S. investment in health care is $\$ 2$ trillion, roughly 16 percent of the gross domestic product (GDP). Of great concern is the fact that health care costs are rising at two-and-one-half times the rate of inflation. Knowing this, health care insurance agencies are responding by examining ways to provide cost effective care. One way to save money is to shift costs to employees through premium increases, higher deductibles, and more out-of-pocket payments.

Medical tourism started off as an option for mostly uninsured who were willing to pay out of pocket to travel overseas to save significant amounts of money when compared to the cost of the same procedure in the U.S. Today there is a new trend emerging where employers and health care insurance companies are looking overseas for cost effective care for employees needing these same procedures (www.medicaltourismassociation.org).

The insurance industry has become an active participant in medical tourism. Many U.S. companies are initiating policies with out-of-country travel options in their health insurance plans (Yi, 2006). West Virginia has considered legislation that provides financial incentives to state employees willing to travel outside the United States for health care (Appleby and Schmidt, 2006). In several states, Blue Cross Blue Shield sells insurance policies that enable or encourage patients to have expensive surgical procedures at low-cost offshore medical facilities (Appleby and Schmidt, 2006; Van Dusen, 2007). Blue Shield of California, for example, allows enrollees to have access to cheaper primary health care across the Mexican border. Blue Cross of South Carolina allows treatment at the Bumrungrad International Hospital in Thailand. Additionally, foreign countries frequently supply low-cost drugs and drug ingredients to U.S. consumers overseas (Hanson, 2008).

Cost accounting plays a role in reducing the financial burden of employee health care. As a result, several Fortune 500 corporations are evaluating the feasibility of outsourcing expensive medical procedures to offshore 
health care destinations (Van Dusen, 2007). As the health care marketplace becomes more global, insurance provider networks include physicians from other countries. In response to health care services offered at a much lower rate, it is anticipated that within a decade a majority of large employers' health plans will include offshore medical centers (Van Dusen, 2007). Insurance companies anticipate that they will have substantial savings by covering outsourced services. These cost savings may provide insurance companies the ability to offer incentives to beneficiaries, such as waiving deductible and out-of-pocket health expenses, and perhaps paying for travel for the patient and even a family member.

Some U.S. hospitals are examining their own bottom line to seek ways to offer comparable prices on medical services offered overseas. These hospitals are counting on competing by offering cost effective procedures without an extended stay away from home, and without a 15-20 hour plane ride back from foreign countries. At a time the U.S. economy is in a recession, hospitals want to fill beds during lower-volume periods. Therefore, they are competing for dollars from underinsured individuals willing to pay out-of-pocket for quality, discounted medical procedures such as heart surgery, hip replacement, and a wide range of cosmetic procedures. Some hospitals have sought out companies such as Healthbase, who typically work with overseas medical providers to arrange for U.S. citizens to travel abroad to get health care. U.S. hospitals see the potential to attract individuals from other countries such as Canada to the U.S., to pay out of pocket for certain medical procedures.

It has been suggested that instead of viewing medical tourism as competition, health care companies in other countries may some day be viewed as "links" in a global, offshore supply chain. Large for-profit U.S. hospital chains may one day embrace the idea of routinely outsourcing some types of care to these countries. This is especially true if the procedures offered are safe, low margin, and high volume (Lindsay, 2008).

\section{QUALITY AND SAFETY CONCERNS}

When faced with a decision to seek care in another country, many individuals are faced with concerns over quality and safety. In the U.S., health care is highly regulated by federal standards. Most individuals choosing health care do not have adequate knowledge to make decisions to ensure their own safety. Therefore, some medical tourism agents provide useful information for patients to make appropriate choices. Accreditation by the Joint Commission International, which has accredited more than 125 facilities in 24 countries, and/or the International Organization of Standardization may provide a useful point of reference for patients selecting offshore medical facilities.

To address the need for quality standards, an international subsidiary of Joint Commission International certifies agencies providing care. To date more than 250 foreign hospitals in 33 countries are certified by Joint Commission International. The American Medical Association also advocates that insurance companies adhere to specified principles of quality. One of the most significant principles is that coverage for travel outside the U.S. for medical care must include costs of necessary follow-up care upon return to the U.S. The AMA does not, however, speak to the financial responsibilities when complications arise that are associated with the combination of surgical procedures, long flights, and vacation activities.

The Medical Tourism Association has launched its Quality of Care Project, which will change global health care. Currently patients, insurance companies, and employers from around the world cannot compare or assess a hospital's quality of care, because each hospital uses a different "methodology" in how they collect and report hospital statistics and quality indicators. Leading hospitals from around the world have agreed to work with the Medical Tourism Association to create a "single methodology" for reporting. This project will change Global Health care as we know it. For the first time ever, patients, employers, and insurance companies around the world will be able to compare the top international hospitals' quality of care. The information gathered from this quality of care project will be posted on the Medical Tourism Association's website, which allows people to view the quality of care of international hospitals online in one place. This project should help the growth of medical tourism and help patients to feel more comfortable and confident when going overseas for surgery. This project was launched as a part of the Medical Tourism Association's mission to provide "transparency" regarding quality of care data in the Medical Tourism / Global Health care world (www.medicaltourismassociation.com). 
Concerns have been voiced regarding the risk of surgical complications resulting from travel and vacation activities. Decisions regarding length of stay in a country to obtain follow up care during the post-operative period are difficult, especially if an extended stay contributes to the expense. In the end, some may feel the benefits of cost savings did not offset the time and money spent addressing complicated follow up care. The consequent costs of this care are difficult issues that remain unresolved (Horowitz, Rosenweig, and Jones 2007).

Because quality of health care around the world varies, there are concerns over receiving substandard care. There is very little research on complications and the costs associated with negative medical outcomes. The few studies that have addressed patient outcomes for organ transplants for those who outsourced care to China, India, and Pakistan suggests that commercial out-of-country transplantation substantially increases morbidity and mortality rates (Canales, Kasiske and Rosenberg, 2006; Kennedy et al, 2005; Prasad, Shukla, Huang, D’A Honey, and Zaltzman, 2006).

Disruption in continuity of care is another problem associated with unanticipated costs. In most health care models, family physicians ideally interact with specialists and remain involved in patient care throughout the course of treatment. It is possible to stay connected, but there is no incentive for specialists in another country to keep family physicians abreast of the care or complications experienced while in another country. Further complicating the management of health care is the individual who chooses to pay out-of-pocket expenses to overseas medical care providers without choosing to inform the domestic physician or health care medical insurance provider.

What is not known is the impact of medical tourism on health and recovery? Research has demonstrated improved well being associated with vacationing/traveling. If the appeal of medical tourism is to extend a trip after medical treatment, then the benefits of this experience must be assessed from all aspects.

\section{SUMMARY AND CONCLUSIONS}

A developing trend has emerged wherein citizens of highly developed countries choose to bypass care offered in their own communities and travel to less developed areas of the world to receive a wide variety of medical services (Horowitz, Rosenweig, and Jones 2007). With deductibles averaging $\$ 1000$ or more for many individuals who purchase affordable health care coverage, the demand for cost-effective procedures is on the rise. Additionally, the opportunity to have elective surgery, and then to vacation in a foreign country, has spurred growth in the medical tourism industry. Medical tourism presents important concerns and challenges, as well as potential opportunities. This trend will have an increasing impact on the globalization of health care among industrialized and developing countries around the world.

Not surprisingly, even though there is an appeal for obtaining health care as part of a "travel package", the recreational value of travel has decreasing importance to patients with complex, serious medical problems (Horowitz, Rosenweig, and Jones 2007). Physicians and hospitals in medical tourism destinations recognize that they must provide high-quality care to develop a sustainable, competitive advantage in the international marketplace. There are many reasons to believe that if quality and patient safety can be adequately addressed through international standards, that the trend toward medical outsourcing will continue to grow and evolve.

\section{AUTHOR INFORMATION}

Paul J. Carruth, Ph.D., CPA is a Professor of Accounting at Southeastern Louisiana University.

Ann K. Carruth, DNS, RN is a Professor of Nursing and Graduate Nursing Program coordinator at Southeastern Louisiana University

\section{REFERENCES}

1. Appleby J, Schmidt J. Sending patients packing. USA Today. July 26, 2006. Available at http://www.usatoday.com/money/industries/health/2006-07-26-travel-surgery-usat_x.htm Accessed October 2, 2009. 
2. $\quad$ author (2008, August $16^{\text {th }}$ ) Importing competition. The Economist, 388 (8593). 12, 74-76.

3. Baliga H. Medical tourism is the new wave of outsourcing from India. India Daily. December 23, 2006. Available at http://www.indiadaily.com/editorial/14858.asp Accessed October 2, 2009.

4. $\quad$ Beat waiting lists with overseas op. Daily Express (UK). July 3, 2005.

5. Canales M, Kasiske B, Rosenberg M. (2006). Transplant tourism: outcomes of United States residents who undergo kidney transplantation overseas. Transplantation. 82 (12),1658-61.

6. Chinai, R., \& Goswasmi, R. (2007, March). Medical visas mark growth of Indian medical tourism. Bulletin of the World Health Organization. 85 (3), 164-165.

7. Comarow, A. (2008, May 12). Under the knife in Bangalore. .U.S. News and World Report. 42-50.

8. $\quad$ Eggertson L. (2006). Wait-list weary Canadians seek treatment abroad. CMAJ, 174 (9), 1247.

9. Great Indian hospitality can be biz too. The Economic Times (India). July 29, 2005.

10. Hanson, F. (2008). A revolution in health care. Institute of Public Affairs Review. 59 (4), $42-45$.

11. Horowitz, M.D., Rosensweig, J.A., \& Jones, C.A. (2007). Medical tourism: Globalization of health care marketplace. MedGenMed, 9 (4), 33.

12. Joint Commission International. www.jointcommisioninternational.org accessed Oct 2, 2009.

13. Kennedy S, Shen Y, Charlesworth J, Mackie J, Mahony J, Kelly J, et al. (2005). Outcome of overseas commercial kidney transplantation: an Australian perspective. Med J Aust. 182 (5), 224-7.

14. Koster, K. (2009, February). Spurred by economy, medical tourism poised for breakout in '09. Employee Benefit News, 23 (2), 38.

15. Lancaster J. Surgeries, side trips for medical tourists. p. A1. Washington Post. October 21, 2004.

16. Lindsay, G. (2008). Medical leave. Fast Company, 125, 108-119.

17. Lubell, J. (2009). New tourist attractions. Modern Health care, 39 (24) 28-30.

18. McCallum, B.T., \& Jacoby, P.F. (2009, January). Medical outsourcing: Reducing client's health care risks. Benefits and Compensation Digest, 46 (1) 26-32.

19. Medical Tourism Association, www.medicaltourismassociation.com accessed Oct 2, 2009.

20. Miller, R.K. \& Washington, K. (2009). Medical tourism. Consumer Health care, 144-146.

21. Prasad GV, Shukla A, Huang M, D’A Honey RJ, Zaltzman JS. Outcomes of commercial renal transplantation: a Canadian experience. Transplantation. 2006;82:1130-5.

22. Turner, L. (2007, October). Medical tourism: Family medicine and international health-related travel. Canadian Family Physician. 53 (10), 1639-1641.

23. Van Dusen A. Outsourcing your health. Forbes Web site. May 22, 2007. Available at http://www.forbes.com/2007/05/21/outsourcing-medical-tourism-bizcx_avd_0522medtourism.html?partner=email Accessed June 28, 2007.

24. Yi D. (2006). Overseas surgery a clamp on costs. Los Angeles Times. Jul 30, Sect. A:1. 